\title{
DIREITO À PRIVACIDADE: UMA NOVA PERSPECTIVA
}

RIGHT TO PRIVACY: A NEW PERSPECTIVE

DERECHO A LA PRIVACIDAD: UNA NUEVA PERSPECTIVA

José Isaac Pilati ${ }^{1}$

Mikhail Vieira Cancelier de Olivo²

Resumo: O nível tecnológico alcançado com os mecanismos de sensoriamento proporciona uma abrangência no acesso a informações - pessoais ou governamentais - jamais imaginado. A privacidade, dessa forma, sai do âmbito puramente privado e ganha contornos coletivos, demandando uma nova forma de análise e tutela. Tal concepção coletiva do bem jurídico - privacidade - supera as barreiras do paradigma jurídico moderno, exigindo nova moldura interpretativa. A teoria da pós-modernidade jurídica possibilita essa nova forma de interpretação.

Palavras-chave: Acesso à informação. Direito à privacidade. Bens coletivos. Constituição. Pós-modernidade jurídica.

Abstract: The current technological level reached by the censoring mechanisms provides access to information - public

1 Professor Doutor nos cursos de graduação e pós-graduação em Direito da Universidade Federal de Santa Catarina. Florianópolis, Santa Catarina, Brasil. jipilati@matrix.com.br.

2 Doutorando em Direito pela Universidade Federal de Santa Catarina. Mestre em Direito e Relações Internacionais pela Universidade Federal de Santa Catarina. Florianópolis, Santa Catarina, Brasil. mikhailcancelier@gmail.com. 
or private - in a way never before imagined. Thus, privacy leaves the exclusively private domain, and takes on a collective nature, requiring a new form of analysis and legal protection. This collective conception of privacy overcomes the obstacles imposed by the modern legal paradigm, requiring a new interpretive framework. The legal theory of postmodernity allows this new form of interpretation.

Keywords: Access to information. Right to privacy. Collective goods. Constitution. Legal postmodernity.

Resumen: El nivel tecnológico alcanzado con los mecanismos de sensoramiento proporciona un alcance jamás imaginado en el acceso a las informaciones, ya sean personales o gubernamentales. De esta manera, la privacidad sale del ámbito puramente privado y gana contornos colectivos, demandando una nueva forma de análisis y tutela. Tal concepción colectiva del bien jurídico - privacidad - supera las barreras del paradigma jurídico moderno, exigiendo un nuevo marco interpretativo. La teoría de la posmodernidad jurídica posibilita esa nueva forma de interpretación.

Palabras clave: Acceso a la información. Derecho a la privacidad. Bienes colectivos. Constitución. Posmodernidad jurídica.

\section{INTRODUÇÃO}

s inovações tecnológicas impõem à sociedade contemporânea uma
nova realidade social; marcada, dentre outros fatores, por limites
cada vez mais frágeis entre o público e o privado. Esses conceitos foram alterados de forma radical com a disseminação da Internet que, via redes sociais, praticamente extinguiu as possibilidades de isolamento humano. 
Contudo, para além das alterações sociais do mundo on-line, o que se percebe é que as tecnologias de sensoriamento, utilizadas para adquirir informações sobre o que/quem quer que seja, passaram a integrar o cotidiano de forma indiscriminada, fazendo com que haja uma crescente e constante interferência por parte do Estado - principal usuário dessas tecnologias - na esfera da vida privada.

Os sistemas de satélites existentes dão conta de adquirir informações relativas a qualquer espaço que se deseje e os bancos de dados virtuais permitem que diversas informações pessoais sejam acessadas sem qualquer tipo de autorização de seus detentores. Os dados, em sentido bastante amplo, circulam e são analisados pelos detentores dessas tecnologias - em sua maioria Agências Governamentais -, em uma relação marcada pela ingerência e pelo desequilíbrio. ${ }^{3}$

O que se percebe é que a informação adquiriu valor e importância inimaginados, fazendo com que não se meçam esforços para adquiri-la. Dessa forma, a tecnologia passou a permitir o acesso a dados privados, que deveriam ficar restritos à intimidade de seus possuidores, sem possibilitar qualquer tipo de defesa contra tal invasão.

Esses fatores ganham ainda maior relevância quando observados além do âmbito privado, sob o prisma da coletividade. Nesse sentido, a se considerar a Sociedade como sujeito de direito, e detentora de bens coletivos - dentre os quais, o da privacidade - o que se verifica é o amplo desrespeito, por parte do Estado, a essa titularidade. Tal forma de pensar a Sociedade encontra respaldo na teoria da Pós-Modernidade jurídica, que supera a dicotomia Estado/Indivíduo e apresenta como terceiro elemento o Coletivo, cuja institucionalização transforma e atualiza a matriz paradigmática da Modernidade ${ }^{4}$.

3 Sobre esta temática, ver mais em: OLIVO, Mikhail Vieira Cancelier de Olivo. Sensoriamento remoto e propriedade intelectual. Disponível em: https://repositorio.ufsc.br/ handle/123456789/107352. Acesso em: $18 \mathrm{dez}$. 2013; Sensoriamento Remoto e Direito Espacial. Florianópolis: Lagoa Editora, 2010.

4 PILATI, José Isaac. A dimensão filosófica da Pós-Modernidade jurídica: ponto de partida de uma reconstrução paradigmática. Revista Sequência no 63. Florianópolis: Fundação Boiteux, dez. 2011, p. 291; 295. 


\section{A VIOLAÇÃO EM VOGA}

Embora sendo apenas um exemplo dessa interferência, os recentes acontecimentos envolvendo o sistema de espionagem do governo americano, que vieram ao conhecimento público com a denúncia efetuada por um de seus antigos executores, trazem o debate acerca dessa privacidade como bem coletivo - no sentido de bem de todos, na esfera de Sociedade. A título de ilustração, de acordo com o ex-consultor de agências de segurança do governo norteamericano, Edward Snowden, os Estados Unidos têm capacidade de acesso a praticamente todo tipo de ação executada pelos internautas: "perto de 42 bilhões de registros foram capturados pelo programa usado pela Agência Nacional de Segurança dos Estados Unidos (NSA, na sigla em inglês) em um único mês de 2012, e meio trilhão de capturas de dados eram feitas anualmente". Ainda, foi divulgado pelo jornal britânico "The Guardian" que, possivelmente, o esquema teve apoio de gigantes da informática como Google, Facebook e Microsoft. "As empresas negaram colaboração nos grampos e pediram ao governo americano permissão para divulgar as solicitações que receberam". Contudo, a NSA respondeu afirmando que, "graças ao programa de monitoramento dos EUA, mais de 300 terroristas foram capturados" ${ }^{5}$.

Documentos apresentados por Snowden demonstram que o acesso aos dados é constante e em larga escala, sendo que, conforme já exposto, tal acesso seria efetivado por meio de empresas americanas e também via interceptação de satélites. ${ }^{6}$

Após suspeitas de que os EUA espionam fortemente os brasileiros através da internet, o governo sugeriu uma mudança no Marco Civil projeto de lei que definirá os direitos e deveres na internet brasileira. Ele ganhou um novo artigo, que obriga certas empresas a manter,

5 UOL. Snowden obtém status de refugiado na Rússia e deixa aeroporto de Moscou. Disponível em: <http://noticias.uol.com.br/internacional/ultimas-noticias/ 2013/08/01/ snowden-obtem-status-de-refugiado-na-russia-e-deixa-aeroporto-de-moscou.htm> Acesso em 21 jan. 2014.

6 VENTURA, Felipe. Brasil é alvo prioritário de espionagem americana pela internet; governo cobra explicações. Disponível em: http://m.gizmodo.uol. com.br/brasil-espionagem-eua/. Acesso em: 21 jan. 2014. 
em data center no Brasil, uma cópia dos dados pessoais de usuários brasileiros. $^{7}$

Depois da ampla repercussão que as informações sobre o programa de espionagem patrocinado pela Agência norte-americana de segurança provocaram, em especial por envolver dirigentes de países como Brasil, Alemanha e Israel, o presidente Barak Obama anunciou em janeiro de 2014 a reformulação do programa da NSA, para proibir a obtenção de dados relativos aos chefes de Estado de "nações amigas".

Entre as novas medidas, destacam-se: a) A NSA só poderá rastrear telefonemas que estejam, com dois graus de separação, associados a um telefone ligado a uma organização extremista; b) Os detalhes dos telefonemas devem ser protegidos por terceiros, e a NSA terá de obter autorização judicial para ter acesso a essa informação; c) O Departamento de Justiça trabalhará em conjunto com a inteligência para garantir que o banco de dados de telefones só possa ser acessado após decisão judicial ou em uma emergência; d) Criação de um painel de advogados externos como observadores independentes.

Paralelo às medidas tomadas pelo presidente norte-americano, em resposta a uma ação movida por um ativista que teve seu aparelho de celular monitorado, o juiz federal Richard Leon, de Washington, considerou que a prática de espionagem da NSA se configura como uma "invasão arbitrária" da privacidade dos cidadãos, caracterizando-a como uma afronta indiscriminada à privacidade, por se tratar de medida tomada sem aprovação judicial. ${ }^{8}$

Ruaro e Rodriguez salientam que, nos Estados Unidos, a edição do "Patriot Act", após o ataque de 11 de Setembro, criou mecanismos de defesa capazes de identificar as organizações armadas e os seus financiadores, o que gerou o aumento do poder e de controle estatal sobre imigrantes e estrangeiros, proporcionando:

7 VENTURA, Felipe. Governo cobra Google para instalar data center no Brasil, mas empresa resiste. Disponível em: http://m.gizmodo.uol.com.br/governo-google-datacenters/. Acesso em: 21 jan. 2014.

8 BBC. Obama nega espiar líderes estrangeiros e anuncia mudanças na NSA. Disponível em: <http://www.bbc.co.uk/portuguese/noticias/2014/01/ 140117_obama_nsa_pai.shtml>. Acesso em: 19 jan. 2014. 
[...] o aumento do poder de agências do governo na interceptação telefones, e-mails, dados médicos, financeiros, etc., além de alterar muitas leis em relação à privacidade (v.g. Electronic Communication Privacy Act, de 1986). Esta postura estadunidense enfraqueceu em muito a tutela dada às garantias individuais e da privacidade. Podem ser constatadas, a partir dela, ofensas pelo menos às $1^{\text {a }}, 4^{\text {a }}$ e $14^{a}$ Emendas, frente a mandados amplos e abusivos, coletas de dados privados, detenções injustificadas. ${ }^{9}$

Sobre o direito de proteção dos dados pessoais no Brasil, Ruaro e Rodriguez destacam que ele é tratado "de forma superficial em legislações esparsas e fragmentadas, como no Código de Defesa do Consumidor e em leis penais", para salientar que "sua existência só assume importância diante de eventos danosos à nossa individualidade, à privacidade e à intimidade, quando então alguns de nós buscamos recompor o dano através de ações judiciais". ${ }^{10}$

\section{UM NOVO PARADIGMA JURÍDICO}

O que se comprova e examina nesse nível de desenvolvimento tecnológico é a transformação que ele opera no cotidiano de todos. Pois, é de tal ordem de magnitude e abrangência que está a exigir um debate acerca de seus limites. Logo, se por um lado são incontáveis os benefícios aportados pela constante inovação, por outro isso permite interferência em ambientes fundamentais à vida, muitas vezes descaracterizando-os e redefinindo-os ${ }^{11}$; e essa alteração de perspectiva projeta reflexos na definição do "privado".

Ao mesmo tempo, e em passos mais lentos, o Direito também evolui e procura readequar-se às novidades fáticas, nem sempre com êxito. Assim, se 9 RUARO, Regina Linden; RODRIGUEZ, Daniel Piñeiro. O direito à proteção de dados frente a medidas de segurança e intervenção estatal. Revista NEJ - Eletrônica, Vol. 15 - n. 2 / mai-ago 2010, p. 280.

10 RUARO, Regina Linden; RODRIGUEZ, Daniel Piñeiro, p. 274.

11 Nesse sentido, Olivo, traz a definição da Sociedade em Rede que, segundo o autor é "a configuração que em determinado momento possibilita que as relações entre setores diversos da economia, das organizações ou da cultura de um povo, realizem-se por meio de redes virtuais de comunicação digitais. As redes virtuais, a exemplo da Internet, são estruturadas como teias não-lineares, interligadas por nós, vinculadas ao protocolo padrão TCP/IP. Cada vez mais as relações se operam de maneira vinculada, integrada, concentrada. Os órgãos, entidades e instituições trocam, fazem circular e armazenam gigantesca quantidade de informações públicas e privadas." OLIVO, Luis Carlos Cancellier de. A reglobalização do estado e da sociedade em rede na era do acesso. Florianópolis: Fundação Boiteux, 2004, p.25 
em alguns campos do comportamento humano o atual paradigma jurídicomoderno funciona, em outros, como nos debates sobre bens de natureza coletiva, vem fracassando. Nesse sentido, acredita-se que o desenvolvimento de uma teoria da pós-modernidade jurídica possa socorrer o direito à privacidade ${ }^{12}$ - constitucionalmente previsto, no artigo $5^{\circ}$, inciso $X-$, começando-se pelo primeiro passo, de considerar a privacidade, como um bem coletivo.

É justamente no viés da necessária adequação jurídica que Bobbio ${ }^{13}$, ao tratar das Eras do direito, já adiantava:

[...] não é preciso muito imaginação para prever que o desenvolvimento da técnica, a transformação das condições econômicas e sociais, a ampliação dos conhecimentos e a intensificação dos meios de comunicação poderão produzir tais mudanças na organização da vida humana e das relações sociais que se criem ocasiões favoráveis para o nascimento de novos carecimentos e, portanto, para novas demandas de liberdade e de poderes.

Verifica-se que, enquanto a substância evoluiu, a forma foi deixada para trás: o privado já não se circunscreve ao privado tradicional, mas transborda também para o coletivo. Busca-se, assim, resgatar esse coletivo para a pós-modernidade, "superando os limites estritos dos interesses difusos e a cultura reinante de tutelar o coletivo com instrumentos jurídicos do processo privado tradicional"14; pois que a pós-modernidade, no Direito, não se pauta pelo monismo jurídico, mas pelo pluralismo de fontes, baseando-se nos instrumentos constitucionais, valorizando e redefinindo os procedimentos de tutela para os bens coletivos, em que predomina a dimensão participativa.

Em outras palavras:

12 Art. $5^{0}$ Todos são iguais perante a lei, sem distinção de qualquer natureza, garantindo-se aos brasileiros e aos estrangeiros residentes no País a inviolabilidade do direito à vida, à liberdade, à igualdade, à segurança e à propriedade, nos termos seguintes:

$[\ldots]$

X - são invioláveis a intimidade, a vida privada, a honra e a imagem das pessoas, assegurado o direito a indenização pelo dano material ou moral decorrente de sua violação [...]."

13 BOBBIO, Norberto. A era dos direitos. 10. ed. Trad. de Carlos Nelson Coutinho, Rio de Janeiro: Campus, 1992, p.33.

14 PILATI, José Isaac. Propriedade e função social na pós-modernidade. 3. ed. Rio de Janeiro: Lumen Juris, 2013, p.17. 
Eliminando da ordem jurídica o titular dos bens coletivos (a Sociedade), a modernidade individualista suprime a dimensão participativa [...] e preenche tal espaço com o pessoal do Estado munido de poder de polícia. [...]. Ainda que os textos legais atuais assegurem participação, o sistema jurídico ainda não reconhece a Sociedade como titular efetiva daqueles bens que ultrapassam a dimensão de público-estatal [...]. Com isso, também não se criam as tutelas coletivas adequadas e correspondentes aos interesses da Sociedade..$^{15}$

Enquanto o paradigma da modernidade pauta-se na dicotomia liberal - que reduz os bens a públicos (estatais) e privados -, a pós-modernidade insere o "coletivo" como terceira vertente de classificação. Os bens coletivos, dessa forma, ganham autonomia jurídica e a Sociedade é repersonalizada, passando a ser considerada titular de direitos. $O$ exercício desses direitos demanda instrumentos de deliberação e decisão próprios, num ambiente em que toda decisão relacionada a bens ou interesses coletivos obedece ao processo legal participativo.

A República participativa provoca alterações [e] desloca a soberania, em alguns casos, da esfera autocrática e formal do Estado para a coletiva. [...]. A repersonalização do coletivo (como Sociedade) resgata juridicamente o indivíduo como condômino de uma categoria diferenciada de bens, que pertencem a todos por dispositivo constitucional - como direito fundamental extrapatrimonial da coletividade [e] reabilita o coletivo ao exercício de uma nova modalidade de processo, a conviver com o processo tradicional. ${ }^{16}$

O conceito de pós-modernidade, de acordo com Sousa Santos, decorre de uma espécie de acordo linguístico, embora não muito definido, que a comunidade científica adotou em torno do tema, para caracterizar algo que vem depois da modernidade, superando a sociedade industrial, que por sua vez superou a sociedade agrária.

Na falta de uma definição mais precisa, Sousa Santos prefere considerar que a sociedade atual vive uma experiência da transição paradigmática e:

Como todas as transições são simultaneamente semi-invisíveis e semicegas, é impossível nomear com exatidão a situação atual. Talvez seja por isso que a designação inadequada de

15 PILATI, José Isaac. p.103; 106-107. Ver também: PILATI, José Isaac. Conceito e classificação da propriedade na pósmodernidade: a era das propriedades especiais. Florianópolis: Fundação Boiteux. Revista Seqüência, no 59, p. 89-119, dez. 2009.

PILATI, José Isaac. p.141-142. 
'pós-moderno' se tornou tão popular. Mas, por essa mesma razão, este termo é autêntico na sua inadequação. ${ }^{17}$

Também tratando do tema, Bittar acrescenta que a pósmodernidade,

(...) na acepção que se entende cabível, é o estado reflexivo da sociedade ante suas próprias mazelas, capaz de gerar um revisionismo de seu modus actuandi, especialmente considerada a condição de superação do modelo moderno de organização da vida e da sociedade.

O autor considera que não apenas de superação se entende viver a pós-modernidade, mas que "o revisionismo crítico implica praticar a escavação dos erros do passado para a preparação de novas condições de vida". 18

Importante notar que o paradigma pós-moderno não é excludente, e sim inclusivo; a pessoa não é substituída pelo povo. O que se apresenta é a possibilidade de estabelecerem-se novas funções ao Estado e ao indivíduo. O que se procura é "uma decisão de consenso entre condôminos, perante as instituições políticas da soberania popular direta, participativa e não representativa"; é um paradigma participativo, que tem como grande fato propulsor o exercício dos direitos coletivos, na estampa do parágrafo único do artigo $1^{\circ} \mathrm{da}$ CRFB. Em face do coletivo e das suas circunstâncias, a pessoa é guiada ao "ápice da organização social, sem prejuízo das prerrogativas estatais, da segurança e da liberdade"19.

[...] a questão coletiva é um problema concreto, de sobrevivência da Sociedade pós-moderna; e não existe outro meio de contemplar e compor o seu interesse perante tal necessidade, senão definindo novas formas de exercício e de tutela de direitos, os quais não excluem o Estado e os Poderes, mas Ihes modificam determinadas formas de atuação. Trata-se de exercício de direitos fundamentais - e o Estado tem importante papel no seu desempenho; mas em regime de

17 SOUSA SANTOS, Boaventura de. A crítica da razão indolente: contra o desperdício da experiência. São Paulo: Cortez, 2001, p.50.

18 BITTAR, Eduardo Carlos Bianca. O direito na pós-modernidade. Florianópolis: Fundação Boiteux. Revista Seqüência, n 57, p. 131-152, dez. 2008.

19 PILATI, José Isaac. p.145. 
cotitularidade, sob a égide da República participativa e não de direito privado ou administrativo. ${ }^{20}$

Há, igualmente, uma mudança na norma, que deixa de ser meramente representativa, passando a ter seu conteúdo definido pela coletividade, via processo de participação. Contudo, fundamental ater-se ao fato de que a lei continua dependendo da homologação de autoridade competente (Executivo, Legislativo ou Judiciário). Ou seja: "O conteúdo é definido pela coletividade; mas a coletividade sozinha não faz lei participativa, nem a coloca a vigorar. E sempre necessitará do compra-se de uma autoridade." ${ }^{21}$

Daí a crise do paradigma da modernidade, que não mais oferece bases sólidas e adequadas para solucionar os conflitos atuais, criando um descompasso entre o Direito vigente e os problemas contemporâneos. Na busca pela atualização do modelo jurídico, são encontradas nas fontes do Direito romano as estruturas do paradigma pós-moderno. Nesse sentido, a República romana oferece lições como "a organização judiciária civil coletiva, e não público-estatal, mediante processo civil participativo, casuístico e não legalista"22.

O sistema romano buscava a inclusão de todos os cidadãos da República nas decisões tomadas, localizando nesses - embora não de maneira exclusiva, visto ser a soberania exercida por meio dos magistrados eleitos pelo populus a soberania; o direito coletivo não possuía status de direito estatal, muito pelo contrário, cada cidadão era sujeito desse direito, de natureza pública, ou seja, "o que é dos romanos pertence a eles, como espécie de condomínio de mão comum, e não a uma pessoa jurídica que os representa"23.

E mais:

Assim como as leis eram aprovadas sob a direção e o comando de uma magistratura, o processo jurisdicional também se desenvolvia sob o balizamento e a condução do pretor. O pretor não era órgão estatal no sentido moderno, de Estado representativo, separado dos cidadãos [...]. para exemplificar, era como se o pretor fosse um síndico e Roma

20 PILATI, José Isaac. p.147-148.

21 PIALTI, José Isaac. p.148.

22 PILATI, José Isaac. p.85.

23 PILATI, José Isaac. p.151 
um edifício dos dias de hoje: um condômino eleito para presidir o processo de solução das contendas, exercendo os poderes da iuris dictio de acordo com os costumes. ${ }^{24}$

Contudo, a Modernidade trouxe a exaltação da figura do Príncipe, fazendo com que a paisagem jurídica, nas palavras de Grossi ${ }^{25}$ (2007), sofresse radical alteração, reduzindo os atores a, de um lado, o macro-sujeito político e, de outro, o micro-sujeito privado, passando a imperar o Direito estatal monista, retirando o "público" do contexto do coletivo e passando-o ao significado de apropriação estatal. O Direito deixa de ser construído caso a caso, passando a ser deduzido da lei representativa.

Ocorre que, acredita-se, enquanto os bens classificados como coletivos não forem realocados na autonomia original que lhes é de direito, não há como reverter o desequilíbrio existente entre os sujeitos macro e micro, citados por Grossi. Acerca desses bens coletivos, cabem algumas ponderações.

\section{O COLETIVO}

Dessa forma, tais bens têm natureza constitucional, sendo coletivos os bens garantidos, pela Constituição, como fundamentais, que não pertencem, individualmente, a quem quer que seja e dos quais apenas se pode dispor coletivamente ${ }^{26}$. A positivação constitucional da autonomia jurídica desses bens permite que os mesmos não pertençam ao Estado, mas à coletividade, à Sociedade repersonalizada. Ou seja, apenas a Coletividade, por procedimento próprio, pode deles dispor. "O reconhecimento da autonomia confere a eles, mutatis mutandis, a condição de absolutos, de que gozam os direitos reais do direito comum"27.

São, então, oponíveis erga omnes, inclusive ao Estado. Ademais, não sendo possível sua apropriação por particulares, são imprescritíveis e, como pressupostos fundamentais à vida, são perpétuos e necessários.

24 PILATI, José Isaac. p.15.

25 GROSSI, Paolo. Para além do subjetivismo jurídico moderno. Tradução de Ricardo Marcelo Foseca. In: CONGRESSO BRASILEIRO DE HISTÓRIA DO DIREITO. 3, 2007. Curitiba. Digit.

26 PILATI, José Isaac. p.143.

27 PILATI, José Isaac. p.144. 
Significa elevar o coletivo ao mesmo status do privado individualista e com isso redefinir - em campo próprio, conforme dito - o processo, os sujeitos da lide e o direito material coletivos. [...]. Esse sujeito coletivo, que obriga o Estado a atender interesses que se contrapõem aos valores ditados, exclusivamente pela racionalidade econômica, tem contraponto no modelo romano republicano. Observa-se haver no Digesto bens públicos que não são dos particulares nem do Estado e sim da própria coletividade. Não são públicos no sentido de pertencerem a uma pessoa jurídica abstrata, mas a uma corporação [...]. ${ }^{28}$

Também o conceito de propriedade especializa-se e ganha traços coletivos. Nesse sentido, a propriedade coletiva adequa-se aos novos interlocutores, não mais individuais, mas coletivos, relativizando seu objeto, "que antes se restringia aos bens corpóreos, e agora pode abranger verdadeiras entidades ou complexos de situações jurídicas partilhadas coletivamente"29. Tal propriedade é exercida por meio de procedimentos democráticos participativos, de inclusão.

Já no início da década de 2000, Rifkin ${ }^{30}$ apontava para uma nova forma de ver a propriedade:

[...] alguns estudiosos estão começando a sugerir, pelo menos nos círculos acadêmicos, que nossas noções tradicionais de propriedade estão fora de moda. Fragmentos de uma nova teoria de relações de acesso estão começando a aparecer na literatura, embora ainda não estejam presentes no discurso público. Embora uma teoria das relações de acesso bem elaborada ainda precise ser articulada, as discussões já se estendem a ponto de sugerir a possibilidade de um repensar dos relacionamentos sociais nas próximas décadas, à medida que a economia global faz a transição de mercados para redes, do espaço geográfico para o ciberespaço e do capitalismo industrial para o cultural.

PRIVACIDADE

Dentre os bens coletivos - nos termos em que estão sendo tratados aqui - podem ser citados como exemplos o meio ambiente e a cultura, previstos, respectivamente, nos artigos 225 e 216 da CRFB/88. Para além desses, neste

28 PILATI, José Isaac. p.145;147.

29 PILATI, José Isaac, p.47.

30 RIFKIN, Jeremy. A Era do acesso. Trad. de Maria Lucia G.L. Rosa. São Paulo: Makron Books, 2001, p.194. 
artigo, conforme já estabelecido, se objetiva tratar do direito à intimidade e, mais amplamente, à privacidade como bem pertencente à Sociedade.

Diferenciando ambos, Mendes e Branco ${ }^{31}$ definem:

O direito à privacidade teria por objeto os comportamentos e acontecimentos atinentes aos relacionamentos pessoais em geral, às relações comerciais e profissionais que o indivíduo não deseja que se espalhem ao conhecimento público. O objeto do direito à intimidade seriam as conversações e os episódios ainda mais íntimos, envolvendo relações familiares e amizades mais próximas.

Dessa forma, a intimidade pode ser considerada como espécie do gênero privacidade $^{32}$. Contudo, muito se debate acerca do correto uso dessas expressões. Giannotti ${ }^{33}$ não diferencia privacidade de intimidade, sendo ambas as expressões relacionadas ao direito da personalidade garantidor ao ser humano de sua própria condição humana. Celso Lafer ${ }^{34}$, fazendo uso da expressão "direito à intimidade", caracteriza-o como "direito do indivíduo de estar só e a possibilidade que deve ter toda pessoa de excluir do conhecimento de terceiros aquilo que a ela só se refere, e que diz respeito ao seu modo de ser no âmbito da vida privada."

Serpa 35 , por outro lado, adota como base o direito à privacidade, definindo-a como:

[...] um modo específico de vivência pessoal, isolada, numa esfera reservada, consoante escolha espontânea do interessado, primacialmente dentre do grupo familiar efetivo, ou com maior insulamento, mas sempre sem uma notória forma de participação de terceiros, seja pelo resguardo contra a ingerência ou molestamento malévolo alheio, seja pela utilização da faculdade que se lhe é atribuída para razoável exclusão do conhecimento público, de dados, ações, ideias e emoções que the são peculiares.

31 MENDES, Gilmar Ferreira; BRANCO, Paulo Gustavo Gonet. Curso de direito constitucional. 7. ed. São Paulo: Saraiva, 2012, p.318.

32 COSTA JÚNIOR, Paulo José da. O direito de estar só: tutela penal da intimidade. 2. ed. São Paulo: Revista dos Tribunais, 1995, p.36.

33 GIANNOTI, Edoardo. A tutela constitucional da intimidade. Rio de Janeiro: Forense, 1987, p.8; 58; 79.

34 LAFER, Celso. A reconstrução dos direitos humanos: um diálogo com o pensamento de Hannah Arendt. São Paulo: Companhia das Letras, 1988, p.239.

35 SANTA MARIA, José Serpa de. Direito à imagem, à vida e à privacidade. Belém: CEJUP, 1994, p.173. 
Szaniawski ${ }^{36}$ traz, ainda, a expressão "direito ao respeito à vida privada", caracterizando-o como:

[...] uma tipificação dos direitos de personalidade, um direito subjetivo que consiste no poder de toda pessoa assegurar a proteção dos interesses extrapatrimoniais, de impedir a intrusão, a divulgação e a investigação, na sua vida privada, garantindo a paz, a liberdade da vida pessoal e familiar, criando o dever. jurídico em relação a terceiros, de não se imiscuírem na vida privada alheia.

Deixando de lado o debate terminológico, por ora, queda-se com o conceito de José Afonso da Silva ${ }^{37}$, que ensina:

Toma-se, pois, a privacidade como o conjunto de informações acerca do indivíduo que ele pode decidir manter sob seu exclusivo controle, ou comunicar, decidindo a quem, quando, onde e em que condições, sem a isso poder ser legalmente sujeito. A esfera de inviolabilidade, assim, é ampla, abrange o modo de vida doméstico, nas relações familiares e afetivas em geral, fatos, hábitos, local, nome, imagem, pensamentos, segredos e, bem assim, as origens e planos futuros do indivíduo.

Conforme já exposto, a CRFB/88 declara, em seu artigo $5^{\circ}$, inciso $\mathrm{X}$, como invioláveis a intimidade, a vida privada, a honra e a imagem das pessoas. Também a Declaração Universal dos Direitos do Homem, de 1948, protege o direito à intimidade no seu artigo 12, estabelecendo que "Ninguém sofrerá intromissões arbitrárias na sua vida privada, na sua família, no seu domicílio ou na sua correspondência, nem ataques à sua honra e reputação". Ademais, o Pacto da Organização das Nações Unidas sobre Direitos Civis e Políticos (artigo 1738); a Convenção Americana de 1969 sobre os Direitos do Homem (artigo 1139); e a 36 SZANIAWSKI, Elimar. Direitos de personalidade e sua tutela. São Paulo: Revista dos Tribunais, 1993, p.153.

37 SILVA, José Afonso da. Curso de direito constitucional positivo. 32. ed. São Paulo: Malheiros, 2009.

38 ARTIGO 17

1. Ninguém poderá ser objetivo de ingerências arbitrárias ou ilegais em sua vida privada, em sua família, em seu domicílio ou em sua correspondência, nem de ofensas ilegais às suas honra e reputação.

2. Toda pessoa terá direito à proteção da lei contra essas ingerências ou ofensas.

39 Artigo 11 - Proteção da honra e da dignidade

1. Toda pessoa tem direito ao respeito da sua honra e ao reconhecimento de sua dignidade.

2. Ninguém pode ser objeto de ingerências arbitrárias ou abusivas em sua vida privada, em sua família, em seu domicílio ou em sua correspondência, nem de ofensas ilegais à sua honra ou reputação. 
Convenção Europeia de 1950 sobre os Direitos do Homem (artigo 8040) também defendem o direito à intimidade.

\section{CONSIDERAÇÕES FINAIS}

A presença constante e invasiva das novas tecnologias já não é novidade. Da mesma forma - e, também, em virtude da democratização da tecnologia -, os valores relacionados à privacidade vêm sofrendo uma forte readequação conceitual. Ao que parece, compartilhar-se tudo com todos tornou-se uma necessidade crescente da população.

Contudo, é importante notar a diferença entre a divulgação intencional de informações e o gerenciamento indevido delas, principalmente por parte de agências governamentais e empresas do ramo da informática. A despeito das mudanças de comportamento social, o direito à intimidade permanece, e manter o caráter privado das informações pessoais constitui um bem jurídico fundamental.

O problema ganha maior amplitude ao ser analisado sob o prisma do coletivo. Não apenas o indivíduo pode sofrer violação desse bem, mas toda a sociedade, o que transfere o problema para além da perspectiva meramente individual. Sistemas estatais de monitoramento por satélites, dentre outras formas de tecnologia de sensoriamento, têm seu uso indiscriminado, não se justificando a falta de limites à invasão da privacidade da Sociedade - como sujeito de direitos coletivos - pelos detentores dessas tecnologias.

Tal status da Sociedade como sujeito de direitos e detentora de bens coletivos - dentre os quais neste artigo com destaque, a privacidade - exalta a dificuldade

3. Toda pessoa tem direito à proteção da lei contra tais ingerências ou tais ofensas.

40 Artigo 8.0 (Direito ao respeito pela vida privada e familiar)

1. Qualquer pessoa tem direito ao respeito da sua vida privada e familiar, do seu domicílio e da sua correspondência. 2. Não pode haver ingerência da autoridade pública no exercício deste direito senão quando esta ingerência estiver prevista na lei e constituir uma providência que, numa sociedade democrática, seja necessária para a segurança nacional, para a segurança pública, para o bem-estar económico do país, a defesa da ordem e a prevenção das infracções penais, a proteção da saúde ou da moral, ou a proteção dos direitos e das liberdades de terceiros. 
de encontrar embasamento para essa nova perspectiva que já não logra sucesso nas molduras da modernidade.

Parte-se, então, para a busca de fundamentação na teoria da pós-modernidade, que supera a classificação dual - público (estatal)/privado - dos bens, inserindo o coletivo como terceira via, e permite que a Sociedade seja reconhecida como titular efetiva de direitos. Há, dessa forma, o resgate do coletivo como instância autônoma da Sociedade.

Ademais, o paradigma jurídico pós-moderno coloca no primeiro plano a importância do processo legal participativo, com o indivíduo aportado ao status de condômino dos bens coletivos e modificando o espaço ocupado pelo Estado, que passa a ser, ao lado da Sociedade, cotitular nesse processo, permitindo formas adequadas de tutela e exercício dos direitos coletivos.

É essa a perspectiva aqui proposta, a de se estudar a tutela e o exercício da privacidade, como bem coletivo; frente ao risco permanente de invasão da privacidade dos cidadãos e sem obediência a limites. A magnitude do problema é de tal ordem, que a discussão deve ser transportada para as soluções de um novo paradigma.

\section{REFERÊNCIAS}

BITTAR, Eduardo Carlos Bianca. O direito na pós-modernidade. Florianópolis: Fundação Boiteux. Revista Seqüência, n ${ }^{\circ}$ 57, p. 131-152, dez. 2008.

BOBBIO, Norberto. A era dos direitos. 10. ed. Trad. de Carlos Nelson Coutinho, Rio de Janeiro: Campus, 1992.

COSTA JÚNIOR, Paulo José da. $\mathbf{O}$ direito de estar só: tutela penal da intimidade. 2. ed. São Paulo: Revista dos Tribunais, 1995.

GIANNOTI, Edoardo. A tutela constitucional da intimidade. Rio de Janeiro: Forense, 1987.

GROSSI, Paolo. Para além do subjetivismo jurídico moderno. Tradução de Ricardo Marcelo Foseca. In: CONGRESSO BRASILEIRO DE HISTÓRIA DO DIREITO. 3, 2007. Curitiba. Digit.

LAFER, Celso. A reconstrução dos direitos humanos: um diálogo com o pensamento de Hannah Arendt. São Paulo: Companhia das Letras, 1988. 
MENDES, Gilmar Ferreira; BRANCO, Paulo Gustavo Gonet. Curso de direito constitucional. 7. ed. São Paulo: Saraiva, 2012.

BBC. Obama nega espiar líderes estrangeiros e anuncia mudanças na NSA. Disponível em: <http://www.bbc.co.uk/portuguese/noticias/ 2014/01/140117_obama_nsa_pai.shtml>. Acesso em: 19 jan. 2014.

OLIVO, Luis Carlos Cancellier de. A reglobalização do estado e da sociedade em rede na era do acesso. Florianópolis: Fundação Boiteux, 2004.

OLIVO, Mikhail Vieira Cancelier de Olivo. Sensoriamento Remoto e Direito Espacial. Florianópolis: Lagoa Editora, 2010.

Sensoriamento remoto e propriedade intelectual. Disponível em: https://repositorio. ufsc.br/handle/123456789/107352. Acesso em: 18 dez. 2013.

PILATI, José Isaac. Propriedade e função social na pós-modernidade. 3. ed. Rio de Janeiro: Lumen Juris, 2013.

. Conceito e classificação da propriedade na pós-modernidade: a era das propriedades especiais. Revista Sequência nº 59. Florianópolis: Fundação Boiteux, dez. 2009.

A dimensão filosófica da Pós-Modernidade jurídica: ponto de partida de uma reconstrução paradigmática. Revista Sequência nº 63. Florianópolis: Fundação Boiteux, dez. 2011.

RIFKIN, Jeremy. A Era do acesso. Trad. de Maria Lucia G.L. Rosa. São Paulo: Makron Books, 2001.

RUARO, Regina Linden; RODRIGUEZ, Daniel Piñeiro. O direito à proteção de dados frente a medidas de segurança e intervenção estatal. Revista NEJ - Eletrônica, Vol. 15 - n. 2 / mai-ago 2010.

SANTA MARIA, José Serpa de. Direito à imagem, à vida e à privacidade. Belém: CEJUP, 1994.

SILVA, José Afonso da. Curso de direito constitucional positivo. 32. ed. São Paulo: Malheiros, 2009.

SOUSA SANTOS, Boaventura de. A crítica da razão indolente: contra o desperdício da experiência. São Paulo: Cortez, 2001.

SZANIAWSKI, Elimar. Direitos de personalidade e sua tutela. São Paulo: Revista dos Tribunais, 1993. 
UOL. Snowden obtém status de refugiado na Rússia e deixa aeroporto de Moscou. Disponivel em: http://noticias.uol.com.br/ internacional/ultimas-noticias/2013/08/01/ snowden-obtem-status-de-refugiado-na-russia-e-deixa-aeroporto-de-moscou.htm. Acesso em: 21 jan. 2014.

VENTURA, Felipe. Brasil é alvo prioritário de espionagem americana pela internet; governo cobra explicações. Disponível em: http://m.gizmodo.uol.com.br/brasil-espionagem-eua/. Acesso em: 21 jan. 2014.

Governo cobra Google para instalar data center no Brasil, mas empresa resiste. Disponível em: <http://m.gizmodo.uol.com.br/governo-google-data-centers/> Acesso em 21 jan. 2014. 